\title{
Exigência Nutricional de Lisina para Codornas Japonesas (Coturnix coturnix japonica) em Postura
}

\section{Andréia de Mello Oliveira ${ }^{1}$, Antonio Claudio Furlan², Alice Eiko Murakami ${ }^{2}$, Ivan Moreira², Cláudio Scapinello², Elias Nunes Martins ${ }^{2}$}

\begin{abstract}
RESUMO - Um ensaio de desempenho foi realizado para determinar a exigência nutricional de lisina para codornas japonesas (Coturnix coturnix japonica) em postura. Foram utilizadas 288 codornas, com 51 dias de idade, durante quatro ciclos de 21 dias, distribuídas em delineamento experimental inteiramente casualizado com seis tratamentos e seis repetições, sendo a unidade experimental constituída por oito codornas. Uma ração testemunha, contendo níveis adequados de proteína bruta e aminoácidos e outras cinco rações, contendo níveis crescentes de lisina $(0,65 ; 0,85 ; 1,05 ; 1,25 ;$ e 1,45\%) e 14,1\% de proteína bruta foram avaliadas. Excluindo a ração testemunha, as estimativas de exigências, considerando-se porcentagem de postura e peso médio dos ovos, foram 1,07 e 1,08\% de lisina, respectivamente. A ração testemunha com $19,0 \%$ de proteína bruta e 1,0\% de lisina foi suficiente para atender a exigência nutricional deste aminoácido.
\end{abstract}

Palavras-chave: codorna japonesa, desempenho, lisina, porcentagem de postura, peso de ovos

\section{Nutritional Requirement of Lysine for Laying Japanese Quails (Coturnix coturnix japonica)}

ABSTRACT - A performance trial was conducted to determinate the nutritional requirement of lysine for laying Japanese quails (Coturnix coturnix japonica). Two hundred and eighty eight Japanese quails with 51 old days, during four cycles of 21 days, were allotted to a completely randomized design, with six treatments and six replicates, and the experimental unit constituted by eight quails. One control diet, with appropriated levels of the crude protein and amino acids and others five diets, with increasing levels of lysine $(.65, .85,1.05,1.25$, and $1.45 \%)$ and $14.1 \%$ crude protein were evaluated. Excluding the control diet, the estimates of lysine requirements, considering the laying percentage and egg weight average were 1.07 and $1.08 \%$, respectively. The control diet with $19.0 \%$ of crude protein and $1.0 \%$ of lysine was enough to meet the nutritional requirement of this amino acid.

Key Words: Japanese quail, performance, lysine, laying percentage, egg weight

\section{Introdução}

Os resultados de pesquisas sobre a codorna doméstica (Coturnix coturnix japonica), referentes a dados de produção e exigências nutricionais, ainda são poucos, o que dificulta a adoção de programas de alimentação visando, em especial, à produção de ovos, de tal forma que se consiga a maximização da produtividade (MURAKAMI et al. 1993).

Visto que, na exploração de aves, a principal parcela de investimento é a alimentação, que corresponde a aproximadamente $75 \%$ do custo de produção final, e considerando que grande parte do custo da ração é atribuída à proteína, é de grande interesse determinar o nível mínimo que os aminoácidos possam ser utilizados nas rações, sem prejudicar o desempenho das aves.

Apesar do aumento da produção industrial de metionina e lisina - aminoácidos mais limitantes em rações de aves, principalmente, à base de milho e farelo de soja - o custo destes aminoácidos ainda é bastante elevado. Além disso, diversos fatores parecem determinar o requerimento em aminoácidos, destacando-se o nível protéico e energético da ração, a qualidade da proteína, o tipo e a idade da ave.

Para poedeiras leves, vários trabalhos têm indicado a possibilidade de se reduzir o nível protéico das rações, desde que devidamente suplementadas com os referidos aminoácidos (CARMO, 1981; BRAGA, 1984). De acordo com SCHUHMACHER et al. (1993), quando a lisina e a metionina + cistina são supridas de forma marginal, o ganho de peso e a conversão alimentar são mais claramente afetados.

Os melhores resultados de produção de ovos e conversão alimentar para poedeiras leves foram obtidos por BERTECHINI et al. (1995) com o nível de 
0,78\% de lisina na ração. ROSTAGNO et al. (1996) determinaram a exigência nutricional de proteína, lisina e metionina + cistina, para poedeiras leves, em 15,9; 0,793; e 0,679\%, respectivamente.

MURAKAMI et al. (1993) determinaram a exigência de proteína para codornas em crescimento e codornas em postura em, respectivamente, 20 e $18 \%$ $\mathrm{PB}$. A exigência de metionina + cistina para codornas também foi determinada por MURAKAMI et al. (1994) em 0,45\% da ração, porém existe a necessidade em se determinar a exigência de outros aminoácidos essenciais.

Dessa forma, o objetivo deste trabalho foi determinar a exigência nutricional de lisina para codornas japonesas (Coturnix coturnix japonica) em postura.

\section{Material e Métodos}

$\mathrm{O}$ experimento foi conduzido no Aviário da $\mathrm{Fa}-$ zenda Experimental de Iguatemi (FEI) da Universidade Estadual de Maringá, no período de 04 de setembro a 27 de novembro de 1997.

Foram utilizadas 288 codornas com 51 dias de idade, durante quatro ciclos de 21 dias. As aves foram alojados em gaiolas sobrepostas de arame galvanizado com $0,32 \times 0,38 \times 0,16 \mathrm{~m}$, respectivamente, de largura, comprimento e altura, com capacidade de oito codornas/gaiola. O delineamento experimental utilizado foi o inteiramente casualizado com seis tratamentos e seis repetições, sendo a unidade experimental constituída por oito codornas.

Os tratamentos consistiram de uma ração testemunha atendendo às recomendações do National Research Council - NRC (1994) e outra ração deficiente em lisina $(0,65 \%)$ suplementada com níveis de 0,$20 ; 0,40 ; 0,60$; e $0,80 \%$ de lisina, proveniente do produto comercial L-Lisina - $\mathrm{HCl}$ contendo $78,8 \%$ de lisina (Tabela 1).

Peso médio dos ovos, consumo de ração, conversão alimentar $(\mathrm{kg} / \mathrm{kg}$ e $\mathrm{kg} / \mathrm{dz})$ e porcentagem de postura foram obtidos por períodos de 21 dias, sendo a produção de ovos avaliada diariamente e calculada de acordo com o número de codornas por unidade experimental e o peso médio dos ovos, nos últimos cinco dias de cada período.

Os dados foram analisados de acordo com o seguinte modelo estatístico:

em que

$$
Y_{i j}=u+L_{i}+e_{i j}
$$

$\mathrm{Y}_{\mathrm{ij}}=$ valor observado das variáveis estudadas relativo a cada parcela $j$, recebendo nível de lisina $i$; $\mathrm{u}=$ constante geral;

$\mathrm{L}_{\mathrm{i}}=$ efeito do nível de lisina $\mathrm{i}$, sendo $\mathrm{i}=0,65 ; 0,85$; 1,$05 ; 1,25$; e $1,45 \%$; e Yij.

$\mathrm{e}_{\mathrm{ij}}=$ erro aleatório associado a cada observação

As estimativas da exigência de lisina, considerando-se as características de desempenho, foram obtidas mediante o uso do modelo quadrático, em que os graus de liberdade referentes aos níves de lisina foram desdobrados em polinômios.

Para comparação dos resultados obtidos entre a ração testemunha com cada um dos níveis de lisina testados, foi utilizado o teste Dunnett a 5\%.

\section{Resultados e Discussão}

Os resultados de desempenho das codornas submetidas a diferentes níveis de lisina nas rações encontram-se na Tabela 2.

Excluindo a ração testemunha, observou-se efeito quadrático $(\mathrm{P}<0,05)$ dos níveis de lisina sobre a porcentagem de postura, mostrado pela equação $\hat{Y}=39,37+70,01 X-32,60 X^{2}$. O ponto de máximo obtido por esta equação foi 1,07\% de lisina. Este valor é superior ao obtido por SHIM e LEE (1984), porém inferior ao observado por SHRIVASTAV et al. (1984). SHIM e LEE (1985) concluíram que 1,0\% de lisina na ração de codornas é o mais adequado para a melhor performance reprodutiva (maior número de ovos, ovos maiores, maior proporção de fertilidade e eclodibilidade).

O peso médio dos ovos foi influenciado de forma quadrática $(\mathrm{P}<0,07)$, sendo o ponto de máximo obtido pela equação $\hat{\mathrm{Y}}=7,80+2,56 \mathrm{X}-1,19 \mathrm{X}^{2}$, de $1,08 \%$ de lisina.

As estimativas de exigência obtidas para porcentagem de postura e peso médio dos ovos de 1,07 e $1,08 \%$ de lisina são superiores ao nível de lisina contido na ração testemunha $(1,0 \%)$ com nível adequado de proteína. Pode-se concluir que rações com $19,0 \%$ de proteína bruta e $1,0 \%$ de lisina são suficientes para atender às exigências nutricionais deste aminoácido.

O consumo diário de ração e a conversão alimentar, respectivamente, em $\mathrm{kg} / \mathrm{kg}$ e $\mathrm{kg} / \mathrm{dz}$, não foram influenciados pelos níveis de lisina estudados.

Verificou-se, por intermédio do teste Dunnett $(\mathrm{P}<0,05)$, que o menor nível de lisina e o mais elevado proporcionaram os piores resultados na percentagem de postura, concordando com os obtidos por SHRIVASTAV et al. (1990), em que rações com altos níveis de lisina e metionina, individualmente ou 
1052 Rev. bras. zootec.

Tabela 1 - Composição percentual e química da ração testemunha e das rações experimentais (matéria natural) Table 1 - Percentage and chemical composition of the control diet and of test diets (as fed basis)

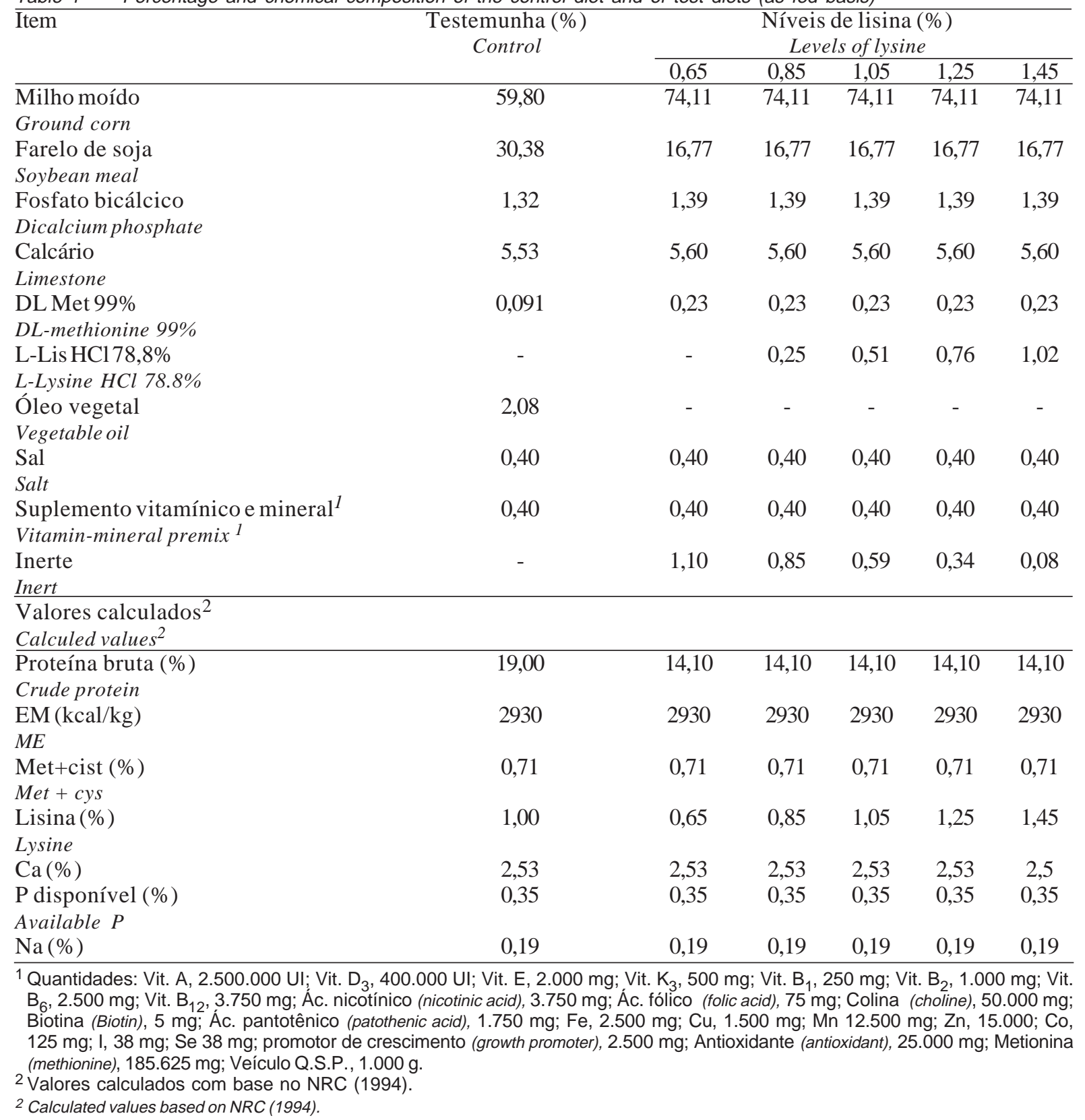

em combinação, resultaram em significante redução na produção de ovos, a qual, na produção com altos níveis de suplementação de lisina e/ou metionina, pode ser atribuída a imbalanços no perfil aminoacídico.

Para peso médio de ovos e consumo diário de ração, todos os níveis diferiram da ração testemunha, verificando-se, portanto, que as rações com baixo nível de proteína $(14,10 \%)$, suplementadas com lisina, não produziram as mesmas respostas que a ração testemunha que continha nível superior de proteína bruta $(19,0 \%)$, ressaltando, dessa forma, a importância da presença de níveis adequados de proteína e/ou outros aminoácidos nas rações. SHIM e LEE (1982) afirmaram que a suplementação de aminoácidos em rações de codornas pode reduzir o requerimento de proteína de 2 a $4 \%$.

A conversão alimentar ( $\mathrm{kg} / \mathrm{kg}$ de ovos) apresentou diferença $(\mathrm{P}<0,05)$ apenas para $0,65 \%$ de lisina. 
OLIVEIRA et al.

Tabela 2 - Porcentagem de postura, peso de ovos, consumo diário de ração e conversão alimentar de codornas submetidas a diferentes níveis de lisina

Table 2 - Laying percentage, egg weight, daily feed intake and feed:gain ratio $(\mathrm{kg} / \mathrm{kg}$ and $\mathrm{kg} / \mathrm{dz})$ of the quails allotted to different levels of lysine

\begin{tabular}{|c|c|c|c|c|c|c|c|}
\hline \multirow[t]{2}{*}{ Item } & \multirow[t]{2}{*}{$\begin{array}{l}\text { Ração testemunha } \\
\text { Control diet }\end{array}$} & \multicolumn{5}{|c|}{$\begin{array}{l}\text { Níveis de lisina (\%) } \\
\text { Levels of lysine }\end{array}$} & \multirow[t]{2}{*}{$\mathrm{CV}(\%)^{1}$} \\
\hline & & 0,65 & 0,85 & 1,05 & 1,25 & 1,45 & \\
\hline $\begin{array}{l}\text { Porcentagem de postura }{ }^{\mathrm{a}} \\
\text { Laving percentage }^{\mathrm{a}}\end{array}$ & 84,57 & $71,61^{*}$ & 74,69 & 75,85 & 78,06 & $71,48^{*}$ & 7,83 \\
\hline $\begin{array}{l}\text { Peso de ovos }{ }^{\mathrm{b}} \\
\text { Egg weight }\end{array}$ & 10,13 & $8,94 *$ & $9,15^{*}$ & $9,14^{*}$ & $9,14^{*}$ & $9,01^{*}$ & 2,51 \\
\hline $\begin{array}{l}\text { Consumo de ração (g/dia) } \\
\text { Feed intake (g/day) }\end{array}$ & 21,66 & $19,82^{*}$ & $19,15^{*}$ & $19,34^{*}$ & $19,56^{*}$ & $18,56^{*}$ & 4,88 \\
\hline $\begin{array}{l}\text { Conversão alimentar }(\mathrm{kg} / \mathrm{kg}) \\
\text { Feed:gain ratio }\end{array}$ & 2,60 & $3,16^{*}$ & 2,84 & 2,98 & 2,88 & 2,99 & 8,57 \\
\hline $\begin{array}{l}\text { Conversão alimentar }(\mathrm{kg} / \mathrm{dz}) \\
\text { Feed:gain ratio }\end{array}$ & 0,32 & 0,34 & 0,31 & 0,33 & 0,32 & 0,32 & 8,47 \\
\hline
\end{tabular}

a Efeito quadrático $(P<0,05)$.

b Efeito quadrático $(P<0,07)$.

* Diferem pelo teste Dunnett $(P<0,05)$.

${ }^{1}$ Coeficiente de variação (\%).

a Quadratic effect $(P<.05)$.

${ }^{b}$ Quadratic effect $(P<.07)$.

* Differ by Dunnett test $(P<.05)$.

${ }^{1}$ Coefficient of variation (\%).

\section{Conclusões}

Em rações com baixo teor protéico $(14,10 \%)$, as estimativas de exigência, considerando porcentagem de postura e peso médio dos ovos, foram 1,07 e 1,08\% de lisina, respectivamente.

A ração testemunha, com $19,0 \%$ de proteína bruta e $1,0 \%$ de lisina foi suficiente para atender às exigências nutricionais deste aminoácido, ressaltando, dessa forma, a importância da presença de níveis adequados de proteína nas rações.

\section{Referências Bibliográficas}

BRAGA, D.F. Exigências nutricionais de lisina e aminoácidos sulfurosos para galinhas poedeiras e de lisina para suínos em crescimento. Viçosa, MG, UFV, 1984. p.186. Tese (Doutorado em Zootecnia) - Universidade Federal de Viçosa, 1984.

BERTECHINI, A.G. TEIXEIRA, A.V., CEREZER, C.E. Níveis de lisina para poedeiras comerciais leves na fase de pico de produção. In: CONFERÊNCIA APINCO'1995 DE CIÊNCIA E TECNOLOGIA AVÍCOLAS, Curitiba, 1995. Trabalhos de Pesquisa... Campinas, FACTA, p.73-74, 1995.

CARMO, M. B. Níveis de proteína e aminoácidos sulfurosos em rações de galinhas poedeiras sob regime de alta temperatura. Viçosa, MG, UFV, 1984. p.104. Dissertação (Mestrado em Zootecnia) - Universidade Federal de Viçosa, 1981.

MURAKAMI, A.E., MORAES, V.M.B., ARIKI, J. et al. 1993. Níveis de proteína e energia em rações para codornas japonesas (Coturnix coturnix japonica) em crescimento. R. Soc. Bras. Zootec., 22(4):534-540.

MURAKAMI, A.E., MORAES, V.M.B., ARIKI, J. et al. 1993. Níveis de proteína e energia em rações para codornas japonesas (Coturnix coturnix japonica) em postura. R. Soc. Bras. Zootec., 22(4):541-551.
MURAKAMI, A.E., FURLAN, A.C., TATEISHI, A. et al. Exigência de metionina de codornas japonesas (Coturnix coturnix japonica) em postura. In: REUNIÃO ANUAL DA SOCIEDADE BRASILEIRA DE ZOOTECNIA, 31, 1994, Maringá. Anais...Maringá: SBZ, p.64, 1994.

NUTRIENT REQUIREMENTS OF POULTRY - NRP. 1994. Washington, D.C., National Academy Press, 9.ed. 45p.

ROSTAGNO, H.S., BARBARINO JR., P., BARBOZA, W.A. Exigências nutricionais das aves determinadas no Brasil. In: SIMPÓSIO INTERNACIONAL SOBRE EXIGÊNCIAS NUTRICIONAIS DE AVES E SUÍNOS, 1996, Viçosa. Proceedings...Viçosa: UFV/DZO, p.361-388, 1996.

SHIM, K.F., LEE, T.K. 1982. Least-cost ration formulation for japanese quail. Singapore J. Primary Ind., 10(1):50-57 (Abstract).

SHIM, K. F., LEE, T. K. 1984. Effect of dietary lysine on egg production of laying japanese quail. Singapore J. Primary Ind., 12(2):88-97 (Abstract).

SHIM, K.F., LEE, T.K. 1985. Effect of dietary lysine on fertility and hatchability of breeding japanese quail. Singapore J. Primary Ind., 13(1):32-37 (Abstract).

SHRIVASTAV, A.K., PANDA, B., AHUJA, S.D. 1984. Lysine requirement of growing japanese quail. Ind. J. Poult. Sci., 19(2):61-64.

SHRIVASTAV, A.K., PANDA, B., SADAGOPAN, V.R. 1990. All vegetable diet with and without lysine and methionine supplementation and productive performance of laying coturnix quails. Ind. Vet. J., 67(10):941-947.

SCHUHMACHER, A., EISSNER, C., GROPP, J.M. et al. Carnitine in fish, piglets and quail. VITAMINE UND WEITERE ZUSATZSTOFFE BEI MENSCH UND TIER, 4, 1993. Proceedings... p.407-412, 1993.

Recebido em: 21/08/98

Aceito em: 23/04/99 